\title{
End-of-Life Assessments and Communication for Dying Patients and Their Families
}

\author{
Eun Kyung Lee, M.S., Hyae Yeong Jeong, M.S. and Kyung Won Kim, M.S.* \\ Hospice Palliative Center, Eunpyeong St. Mary's Hospital, The Catholic University of Korea, Seoul, \\ *Department of Nursing, Uijeongbu St. Mary's Hospital, The Catholic University of Korea, Uijeongbu, Korea
}

\begin{abstract}
End-of-life assessments aim to help dying patients and their families plan clinical interventions in advance and prepare them for a peaceful end of life, in which the patient accepts life and death, and the family accepts the patient's departure. It is important to assess whether death is imminent within a few days, because critical hospice care is provided intensively during that period. The following five changes constitute objective evidence of the end of life: diminished daily living performance, decreased food intake, changes in consciousness and increased sleep quantity, worsening of respiratory distress, and end-stage delirium. As subjective evidence, it is suggested that sensitive perceptions of experienced nurses and the feelings of family members caring for patients should also be considered. When notifying a patient or family members that the end of life is approaching, the members of the multidisciplinary hospice team must communicate with each other, share accurate information, and provide consistent explanations. They must also listen to non-verbal communication in an empathic and supportive manner.
\end{abstract}

Key Words: Hospice care, Hospice and palliative care nursing, Terminal care, Death, Nursing assessment, Communication

\author{
Received July 13, 2021 \\ Revised August 9, 2021 \\ Accepted August 9, 2021
}

\section{Correspondence to}

Eun Kyung Lee

ORCID:

https://orcid.org/0000-0002-6498-1333

E-mail: eunlee72@hanmail.net

\section{INTRODUCTION}

The end of life refers to the period in which death is anticipated within a few days or during hospitalization for acute deterioration of cancer, chronic diseases, or chronic organ failure after an accident, without the possibility of recovery or improvement despite treatment; it also encompasses the slowly-progressing dying process associated with aging or dementia [1]. Since discharge is equated with death for most patients admitted to the hospice ward [2], it is necessary to identify end-of-life patients at the time of admission, immediately determine the phase of the end-of-life process, and develop an appropriate care plan.
The purpose of end-of-life assessments is for the hospice medical staff to plan clinical interventions in advance and help prepare for a peaceful end of life, in which patients can reflect on their lives and accept death, while families deal with the imminent departure of their loved ones [3]. However, the end-of-life process differs greatly depending on age and disease, and it is difficult to predict or determine due to repeated exacerbations and improvements during the dying process [1]. Therefore, end-of-life assessments are a routine, but difficult and challenging, task for medical staff, and they may feel guilty if their patients are not able to spend their last moments with family members due to an incorrect prediction of the timing of the end of life.

This is an Open Access article distributed under the terms of the Creative Commons Attribution Non-Commercial License (http://creativecommons.org/licenses/by-nc/4.0/) which permits unrestricted non-commercial use, distribution, and reproduction in any medium, provided the original work is properly cited. 


\section{MAIN TEXT}

It is important to assess the end-of-life phases in the hospice ward because if death is imminent, the patient should be transferred to the dying room for short-term intensive care. The 1-month end-of-life period can be categorized into three phases. In phase 1 , which takes place approximately 1 month before death, symptoms such as general malaise, loss of appetite, and insomnia develop, while in phase 2, which occurs within 2 weeks before death, delirium starts to take over [3]. Phase 3, which corresponds to few days before death, is characterized by worsening of weakness, bedridden status, increased duration of sleep and decreased consciousness, decreased food intake, decreased urine output and dark urine color, delirium, increased breathing noise and respiratory secretions, changes in breathing patterns, uneven skin tone, and cold hands and feet [1]. Even if blood pressure is stable, if there is an urgent change in the patient's physical condition such as unstable respiration (respiratory failure), increased acute pain, changes in skin condition, and massive bleeding, it is difficult to determine whether the third phase of the end of life has started, and this uncertainty needs to be explained to families in advance during the early consultation period after admission [4].

The end of life is determined by referring to changes in five objective signs: deterioration in the performance of daily living activities, decreased food intake, changes in consciousness and increased sleep duration, worsening of breathing difficulties, and end-stage delirium. The Palliative Performance Scale is applied using a cut-off of $40 \%$ or less, but it reflects the individual characteristics of the patient and changes from the last 2 3 days or the previous week [3].

If the amount of food intake decreases by more than 50\%, it is necessary to carefully examine the patient's overall functional changes and difficulty in swallowing, the presence of food caught in the windpipe, and food residue in the oral cavity. At the end of life, most patients are in a state of lethargy, wherein their consciousness progressively declines and sleep duration increases; therefore, it is necessary to provide appropriate explanations to patients and their families so that they can accept these symptoms as part of the natural endof-life process. Regarding dyspnea, it is not the presence or absence of symptoms that is important, but the change in the severity or pattern of symptoms. Abnormal breathing patterns such as shallow breathing, accessory muscle breathing, apnea, Cheyne-Stokes respiration, and a growling breathing sound become increasingly common starting 1 week before death. End-stage delirium is a type of fluctuating confusion that gradually makes it difficult to communicate. It requires aggressive pharmacological treatment, but can become worse to the point that it is unmanageable with medicine [3].

In clinical practice, in addition to the objective evidence presented above, it is also necessary to carefully examine subjective evidence that indicates the end of life is approaching through the sensitivity of seasoned hospice nurses and the feelings of the family members who watch the patients most closely. Kwon et al. [5] stated that nurses' experience of "sensitive nursing" appears to be based on four factors: reflective thinking as a nurse, intuition, a receptive attitude toward death, and an open mind about teamwork with colleagues [5].

However, even if it is determined that a patient is entering the end of life based on objective and subjective evidence, and appropriate steps are taken to prepare, the actual end of life can be different from expectations. Therefore, it is necessary to explain the end-of-life process to families multiple times and wait alongside the patients and their families.

It is necessary to check how patients and their families perceive the medical situation and the doctor's explanations, as well as to assess their needs until the last minute, through communication, accurate information-sharing, and consistent explanations from each member of the hospice multidisciplinary team [3]. In general, patients hope they do not suffer from pain until the last moment and expect sincerity, forgiveness, and reconciliation from those around them. They are also interested in evidence of the afterlife and wish to die with dignity in a familiar place [6]. Families try to do their best to help the patients, want to be kept updated on patients' condition and end of life, and wish to be at their loved one's deathbed [7]. Therefore, by listening to patients and their families, the medical staff can find out what they want to resolve and whom they want to meet.

Various theories and communication skills are used to inform patients and their families of the end of life. Before meeting, all parties need to collect their thoughts, plan thoroughly, set a 
time that is most convenient, and choose a quiet place [1]. It is necessary to identify the level of preparedness and questions of patients and their families to provide accurate information and to empathize and support whenever they appear to be experiencing difficulties.

The family is the "second patient" [8]. Depending on the patient's symptoms, family members may suffer physically and psychologically and present various symptoms of stress [8]; therefore, it is advised to pay close attention to family members, as well as patients, to identify whether they need care.

It is also important to explain any changes in the end-oflife care goals in a way that is acceptable to patients and their families. Repeated explanations are needed so that families can accept and understand that changes do not mean abandonment or discontinuation, but instead reflect essential choices for patients [3]. It is important to avoid using expressions such as "discontinue" or "stop," which are the last words that patients or families like to hear, so that they do not feel abandoned; to check frequently to ensure they do not feel guilty or ambivalent; and to explain the process to them in an easy-tounderstand manner [3].

\section{CONCLUSIONS}

Medical staff can more accurately predict various end-oflife processes through the exchange of information and experiences among members of the multidisciplinary hospice team based on clinical symptoms and signs [1]. To achieve this goal, it is necessary to determine that the end of life is approaching based on close observations of patients from various aspects and thorough communication.

The multidisciplinary hospice team should give hope to $\mathrm{pa}^{-}$ tients during day-to-day life and help them live the rest of their lives meaningfully without regrets. From the moment of admission to the hospice ward, they should develop trusting relationships with patients and their families and offer regular information and explanations according to changes in patients' symptoms and their degree of acceptance thereof. Doing so makes it possible to relieve anxiety. Furthermore, attention should be paid to non-verbal communication, and hospice team members should cultivate an empathic and supportive attitude towards understanding patients' distress [3].

\section{CONFLICT OF INTEREST}

No potential conflict of interest relevant to this article was reported.

\section{ORCID}

Eun Kyung Lee, https://orcid.org/0000-0002-6498-1333

Hyae Yeong Jeong, https://orcid.org/0000-0003-03144993

Kyung Won Kim, https://orcid.org/0000-0002-0826-7792

\section{AUTHOR'S CONTRIBUTIONS}

Conception or design of the work: EKL. Data collection: EKL. Data analysis and interpretation: EKL, KWK. Drafting the article: EKL. Critical revision of the article: EKL, HYJ, KWK. Final approval of the version to be published: EKL, HYJ, KWK.

\section{SUPPLEMENTARY MATERIALS}

Supplementary materials can be found via https://doi. org/10.14475/jhpc.2021.24.3.194.

\section{REFERENCES}

1. Shin J, Chang YJ, Park SJ, Choi JY, Kim SH, Choi YS, et al. Clinical practice guideline care for last days of life. Korean J Hosp Palliat Care 2020;23:103-13.

2. National Hospice Center, Korea Ministry of Health and Welfare. Hospice \& palliative care in Korea; 2019 National hospice palliative care annual report [Internet]. Sejong: Ministry of Health and Welfare; 2019 [updated 2019 Jun 5; cited 2019 Apr 26]. Available from: http://www. mohw.go.kr/react/jb/sjb030301vw.jsp?PAR_MENU_ID=03\&MENU_ID=032901 \&CONT_SEQ=349244. 
3. Park MH. End-of-life care standard guidebook. Seoul, Korea:Leeguil;2018.

4. Research Institute for Hospice/Palliative Care of The Catholic University of Korea College of Nursing. Hospice and palliative care. 2nd ed. Paju:Koonja Publising Inc:;2007.

5. Kwon S, Kim M, Choi S. Nurses's experiences of providing "sensitive nursing care" for terminally-ill individuals with cancer: A qualitative study. Eur J Oncol Nurs 2020;46:101773.

6. Ro YJ. Hospice \& death. 2nd ed. Seoul:HYUNMOON Publishing Co.;1997.

7. National Cancer Control Institute of Korea. Korea Ministry of Health and Welfare. Introduction to hospice palliative care for palliative care team members. Goyang, Korea:NCCl, Ministry of Health and Welfare;2018.

8. Uchitomi Y, Miko F. How to deliver the bad news. Kim JH, Kim MY, Kon ML, Trans. Seoul:National Hospice Center;2008. 